\title{
Longitudinal prediction of falls and near falls frequencies in Parkinson's disease: a prospective cohort study
}

\author{
Beata Lindholm ${ }^{1,2}\left(\right.$ CD $\cdot$ Christina Brogårdh ${ }^{2,3} \cdot$ Per Odin $^{2,4} \cdot$ Peter Hagell ${ }^{4,5}$
}

Received: 12 June 2020 / Revised: 16 September 2020 / Accepted: 17 September 2020 / Published online: 24 September 2020

(c) The Author(s) 2020

\begin{abstract}
Introduction and objective Several prediction models for falls/near falls in Parkinson's disease (PD) have been proposed. However, longitudinal predictors of frequency of falls/near falls are poorly investigated. Therefore, we aimed to identify short- and long-term predictors of the number of falls/near falls in PD.

Methods A prospective cohort of 58 persons with PD was assessed at baseline (mean age and PD duration, 65 and 3.2 years, respectively) and 3.5 years later. Potential predictors were history of falls and near falls, comfortable gait speed, freezing of gate, dyskinesia, retropulsion, tandem gait (TG), pain, and cognition (Mini-Mental State Exam, MMSE). After each assessment, the participants registered a number of falls/near falls during the following 6 months. Multivariate Poisson regression was used to identify short- and long-term predictors of a number of falls/near falls.

Results Baseline median (q1-q3) motor (UPDRS) and MMSE scores were 10 (6.75-14) and 28.5 (27-29), respectively. History of falls was the only significant short-time predictor [incidence rate ratio (IRR), 15.17] for the number of falls/near falls during 6 months following baseline. Abnormal TG (IRR, 3.77) and lower MMSE scores (IRR, 1.17) were short-term predictors 3.5 years later. Abnormal TG (IRR, 7.79) and lower MMSE scores (IRR, 1.49) at baseline were long-term predictors of the number of falls/near falls 3.5 years later.

Conclusion Abnormal TG and MMSE scores predict the number of falls/near falls in short and long term, and may be indicative of disease progression. Our observations provide important additions to the evidence base for clinical fall prediction in PD.
\end{abstract}

Keywords Prediction · Falls/near falls · Tandem gait · Cognition · Parkinson's disease

Beata Lindholm

Beata.Lindholm@med.lu.se

1 Department of Clinical Sciences, Clinical Memory Research Unit, Lund University, Malmö, Sweden

2 Department of Neurology, Rehabilitation Medicine, Memory Disorders, and Geriatrics, Skåne University Hospital, 20502 Malmö, Sweden

3 Department of Health Sciences, Lund University, Lund, Sweden

4 Division of Neurology, Department of Clinical Sciences Lund, Restorative Parkinson Unit, Lund University, Lund, Sweden

5 The PRO-CARE Group, Faculty of Health Sciences, Kristianstad University, Kristianstad, Sweden

\section{Introduction}

Falls and balance problems in Parkinson disease (PD) are common already in the early stages of disease $[1,2]$ and progress over time [3]. In unselected populations, an average of $60.5 \%$ (35-90\%) of persons with PD (PwPD) fell at least once over 12 months, with two-thirds being recurrent fallers [4]. Prospective studies have proposed numerous falls prediction models in PD [5-10]. The most robust predictor for future falls is a history of falls, whereas some observations suggest that a history of near falls has greater clinical value in terms of working proactively to avoid the occurrence of falls [6]. It has also been recommended that prediction models should avoid time-consuming clinical tests and assessments, to facilitate their use in clinical practice [5]. Moreover, a growing body of research highlights the importance of assessing cognition for prediction of falling in PD [11]. The Mini-Mental State Examination (MMSE) is the most 
commonly used screening tool for global cognitive impairment in clinical settings [12] and lower MMSE scores have been suggested as a predictor of falls in PD [13]. However, the significance of predictors based on a single assessment is uncertain given the impact of disease progression on falling. Therefore, prospective cohort studies are needed [14].

Furthermore, the previously proposed prediction models were derived to discriminate future fallers from non-fallers [5-10] and only a few studies investigated the impact of predictors on the frequency of falling $[1,14,15]$. To the best of our knowledge, no study has assessed predictors of the frequency of near falls. Prediction of the frequency of falls/near falls is of great clinical relevance, since a higher frequency may contribute to increased risk for fractures [16, 17]. Therefore, we aimed to identify short- and long-term predictors of the number of falls and/or near falls in PD.

\section{Methods}

\section{Ethics statement}

The Regional Ethical Review Board in Lund, Sweden approved the study (Dnr 2011/768). All participants gave written informed consent to participate.

\section{Study design}

This prospective cohort study includes two clinical assessments: the baseline assessment (A1) at the start of the study and a second assessment (A2) 3.5 years later. After each assessment, participants were instructed to register all consecutive falls and near falls during the following 6 months; first follow-up (F1) and second follow-up (F2), respectively.

\section{Participants}

All people with PD [18] diagnosed by a movement disorder specialist who received care at a south Swedish university hospital at the start of the study were considered eligible for inclusion in the study $(n=349)$. Exclusion criteria at the start of the study were: age above 80 years $(n=116)$, inability to stand without support, i.e., spontaneous tendency to fall in standing position $(n=22)$, unable to understand instructions $(n=14)$, or having severe comorbidity $(n=11)$. Of the remaining 186 potential participants, 40 (16 women) declined participation. The study sample at A1 included 146 PwPD. At the time for A2, 24 PwPD had dropped out due to severe comorbidity or death and 49 (17 women) declined participation. Severe comorbidity included metastatic cancer, stroke, heart failure, dialysis-treated renal failure, agerelated eye diseases, gastrointestinal diseases, and diabetic complications. The final study sample with available A1 and A2 data included 73 PwPD.

\section{Assessment and procedure}

Data on demographics and anti-parkinsonian medications were obtained from medical records. Daily levodopa equivalent (LDE) doses (mg/day) were calculated according to recommended conversion factors [19]. At both A1 and A2, all participants were assessed during outpatient visits, which were scheduled at a time of day when the participant usually reported feeling at his/her best. All PwPD self-rated their motor status at the time of examination as "good/on", "on with dyskinesia", or "bad/off". This was followed by a clinical investigation of nine variables (Table 1) constituting potential predictors for future falls/near falls. In addition, motor symptoms were assessed using the Unified PD Rating Scale (UPDRS) part III (score range, 0-108) [21], and PD severity was classified according to Hoehn \& Yahr (HY) staging (range, I-V) [25]. All assessments were conducted by the same physical therapist (BL).

\section{Follow-up of falls and near falls over 6 months}

PwPD were provided with a diary consisting of pre-printed pages for recording the date and time of every fall/near fall event and questions (yes/no) clarifying whether it was a fall or a near fall. The question in relation to a fall was phrased as follows: Did you fall in such a way that your body hit the ground? The corresponding question about a near fall incident was phrased: Were you close to falling, but managed to brace yourself at the last moment (e.g., grabbed on to someone, to an object or the wall)? Falls were defined as "an unexpected event in which the person comes to rest on the ground, floor, or lower level" [23]. Near falls were defined as "a fall initiated but arrested by support from the wall, railing, other person etc." [24]. The definitions of a fall and a near fall were thoroughly described during the outpatient visit. All participants were telephoned monthly to ensure that registrations had been completed according to instructions. During the last telephone call, they were requested to return the diary in a pre-stamped envelope.

\section{Statistical analysis}

Data were checked regarding underlying assumptions and described accordingly using SPSS version 24 (IBM Corp., Armonk, NY, USA). Normally distributed interval/ratiolevel variables were described using means and SDs. In other cases, medians (q1-q3) were used. Categorical variables were described using $n(\%)$. Wilcoxon signed-rank and McNemar's tests were used for bivariate analysis of 
Table 1 Overview of potential predictors for number of future falls and/or near falls

\begin{tabular}{|c|c|c|c|}
\hline & Description; score range & Dichotomized & References \\
\hline Cognition (MMSE) & $\begin{array}{l}\text { 8-item cognitive screening test; score range } \\
0-30 \text { (higher }=\text { better })\end{array}$ & Not applicable & {$[20]$} \\
\hline Comfortable gait speed m/s (10MWT) & $\begin{array}{l}\text { Time (s) to walk } 10 \mathrm{~m} \text { (without acceleration/ } \\
\text { deceleration distance) in comfortable gait } \\
\text { speed }\end{array}$ & Normal $(\geq 1.1 \mathrm{~m} / \mathrm{s})$, low $(<1.1 \mathrm{~m} / \mathrm{s})$ & {$[5,7,9,10]$} \\
\hline Dyskinesia (item 32, UPDRS) & $\begin{array}{l}\text { Proportion of the waking day with dyskine- } \\
\text { sias; } 0 \text { (none) }-4(76-100 \%)\end{array}$ & No dyskinesias (0), dyskinesias (1-4) & {$[21]$} \\
\hline Freezing of gait (item 3, FOGQsa) & $\begin{array}{l}\text { Do you feel that your feet get glued to the } \\
\text { floor while walking, making a turn or } \\
\text { when trying to initiate walking (freez- } \\
\text { ing)?; } 0 \text { (never)—4 (always_-whenever } \\
\text { walking) }\end{array}$ & No FOG (0), FOG (1-4) & {$[22]$} \\
\hline History of falls & $\begin{array}{l}\text { In the last } 6 \text { months, have you fallen in such } \\
\text { a way that your body hit the ground? } 0 \\
\text { (no)-1 (yes) }\end{array}$ & No history of falls (0), history of falls (1) & {$[23]$} \\
\hline History of near falls & $\begin{array}{l}\text { Are you ever close to falling, but you man- } \\
\text { age to grab on to something/someone at } \\
\text { the last minute so that your body does not } \\
\text { hit the ground? } 0 \text { (no) }-1 \text { (yes) }\end{array}$ & $\begin{array}{l}\text { No history of near falls (0), history of near } \\
\text { falls (1) }\end{array}$ & {$[6,24]$} \\
\hline Pain & $\begin{array}{l}\text { Do you presently suffer from pain? } 0 \\
\text { (no) - } 1 \text { (yes) }\end{array}$ & No pain (0), pain (1) & {$[6]$} \\
\hline Retropulsion (NRT) & $\begin{array}{l}\text { Sudden, unexpected backward pull to the } \\
\text { shoulders from behind when standing } \\
\text { with feet slightly apart and eyes open; } 0 \\
\text { (normal, may take } 2 \text { steps to recover)-3 } \\
\text { (spontaneous tendency to fall or unable to } \\
\text { stand unaided, test not executable) }\end{array}$ & No retropulsion $(0)$, retropulsion $(1-3)$ & [7] \\
\hline Tandem gait (TG) & $\begin{array}{l}10 \text { heal-to-toe steps along a straight line, } \\
\text { with eyes open and without walking aids/ } \\
\text { support (those using walking aids were } \\
\text { asked to try to perform TG without sup- } \\
\text { port); } 0 \text { (no side steps) - } 3 \text { (unable to take } \\
4 \text { consecutive steps) }\end{array}$ & Normal TG (0), abnormal TG (1-3) & [7] \\
\hline
\end{tabular}

FOGQsa freezing of gait questionnaire, MMSE mini-mental state exam, NRT Nutt Retropulsion Test, UPDRS Unified Parkinson's Disease Rating Scale, 10MWT 10-m Walk Test

differences in sample characteristics between A1 and A2. The alpha level of significance was set at 0.05 .

Further analyses were performed through Poisson regression with robust variance. First, simple analyses were performed with each independent variable investigated on A1 and A2 and number of falls and/or near falls investigated at F1 and F2 as a dependent variable. That is, two analyses of short-term predictors were conducted, using A1 and A2 data as independent variables with the number of $\mathrm{F} 1$ and F2 falls/near falls events as dependent variables, respectively. Analysis of long-term predictors included A1 data as independent variables with the number of F2 falls/near falls events as the dependent variable. The incidence rate ratio (IRR) values and $95 \%$ confidence intervals (CI) were calculated. Variables with a $P$ value $<0.20$ in the simple analyses were entered in multiple Poisson regression models. The $<0.2 P$ value threshold was chosen to avoid leaving important variables out [26]. Predictors with the highest $P$ value were subsequently removed by a backwards stepwise deletion approach until only independent predictors with $P$ values $<0.05$ remained in the model. Deviance statistic was used to assess the significance of contribution of each independent predictor included in the models. Overall performance of the final models was evaluated with the Omnibus test (where a $P$ value $<0.05$ suggests adequate goodness-offit) and $R^{2}$ deviance [27]. For the Poisson regression analyses, all predictor scores were adjusted to be in the same direction (higher score $=$ more problems).

\section{Results}

Fifteen of the 73 PwPD were excluded due to incomplete prospective records of falls and near falls. The baseline mean (SD) age and PD duration of the remaining 58 (32 women) PwPD were 65 (8.8) and 3.2 (3.68), respectively, and their 
median (q1-q3) UPDRS III score was 10 (6.75-14). Details regarding results from $\mathrm{A} 1$ and $\mathrm{A} 2$ are provided in Table 2. After 3.5 years, PwPD had more motor symptoms, dyskinesia, and FOG as well as slower comfortable gait speed. In addition, more PwPD reported retrospective falls and near falls, and the number of prospectively reported falls had increased.

\section{Falls and near falls during 6-month follow-up periods}

Twenty-four and twenty-eight PwPD reported at least one fall or near fall during F1 and F2, respectively. The total number of falls was $29(n=13)$ during $\mathrm{F} 1$ and $74(n=26)$ during F2. The mean number of falls (1.28) during F2 was significantly higher $(P=0.007)$ than during F1 (mean, 0.50$)$. The total number of near falls was $122(n=18)$ during F1 and $67(n=19)$ during F2, and the total number of falls and/ or near falls was $151(n=24)$ during F1 and $141(n=28)$ during F2. Neither the mean number of near falls nor falls and/or near falls differed between the two periods (Table 2).

\section{Predictors of number of future falls and near falls}

\section{Short-time predictors}

The univariate Poisson regression analyses, based on results from $\mathrm{A} 1$ and $\mathrm{F} 1$, identified five predictors associated with the number of falls and/or near falls at $P<0.2$ (Table 3). The multivariate Poisson regression analysis identified a model including only history of falls (IRR, 15.17) as a significant predictor of the number of falls and/or near falls during the following 6 months (Table 3).

The univariate Poisson regression analyses, based on results from $\mathrm{A} 2$ and $\mathrm{F} 2$, identified eight predictors associated with the number of falls and/or near falls at $P<0.2$ (Table 4). The multivariate Poisson regression analysis identified a model including two significant predictors of the number of falls and/or near falls during the following 6 months: abnormal TG (IRR, 3.77) and lower MMSE scores (IRR, 1.17) (Table 4).

Table 2 Sample characteristics $(n=58)$

\begin{tabular}{|c|c|c|c|}
\hline & Assessment 1 & Assessment 2 & $P$ value \\
\hline Age (years), mean (SD, min-max) & $65(8.8,43-80)$ & $69(8.9,46-84)$ & NA \\
\hline PD duration (years), mean (SD, min-max) & $3.2(3.68,0.1-17)$ & $6.7(3.68,3.6-20,5)$ & NA \\
\hline HY stage of disease, median (q1-q3) & $2(2-3)$ & $2(2-3)$ & NA \\
\hline Daily total levodopa equivalent (LDE) dose (mg), median (q1-q3) & $200(300-532)$ & $500(400-675)$ & NA \\
\hline \multicolumn{4}{|l|}{ Self-rated motor status at the time of clinical examination } \\
\hline "on" or "on with dyskinesias", $n(\%)$ & $56(97)$ & $48(83)$ & NA \\
\hline "off”, $n(\%)$ & $2(3)$ & $10(17)$ & NA \\
\hline Motor symptoms (UPDRS III), median (q1-q3) & $10(6.75-14)$ & $13.5(9-20.25)$ & $<0.001^{\mathrm{a}}$ \\
\hline Cognition (MMSE), median (q1-q3) & $28.5(27-29)$ & $28(27-29)$ & $0.129^{\mathrm{a}}$ \\
\hline Abnormal tandem gait (TG), $n(\%)$ & $33(57)$ & $38(65.5)$ & $0.302^{\mathrm{b}}$ \\
\hline Dyskinesia (UPDRS IV, item 32), $n(\%)$ & $3(5)$ & $21(36)$ & $<0.001^{\mathrm{a}}$ \\
\hline Comfortable Gait speed $<1.1 \mathrm{~m} / \mathrm{s}(10 \mathrm{MWT}), n(\%)$ & $9(15.5)$ & $24(41)$ & $<0.001^{\mathrm{b}}$ \\
\hline Pain, $n(\%)$ & $18(31)$ & $21(36)$ & $0.481^{\mathrm{b}}$ \\
\hline History of falls, $n(\%)$ & $7(12)$ & $23(40)$ & $<0.001^{\mathrm{b}}$ \\
\hline History of near falls, $n(\%)$ & $17(29)$ & $37(64)$ & $<0.001^{\mathrm{b}}$ \\
\hline Freezing of gait (item 3, FOGQsa), $n(\%)$ & $19(33)$ & $29(50)$ & $0.013^{\mathrm{b}}$ \\
\hline Retropulsion (NRT), $n(\%)$ & $15(26)$ & $19(33)$ & $0.405^{\mathrm{b}}$ \\
\hline Number of falls during 6-month follow-up, mean (SD, min-max) & $0.50(1.53,0-10)$ & $1.28(2.05,0-9)$ & $0.007^{\mathrm{a}}$ \\
\hline Number of near falls during 6-month follow-up, mean (SD, min-max) & $2.10(6.82,0-45)$ & $1.16(2.85,0-16)$ & $0.763^{\mathrm{a}}$ \\
\hline Number of falls and/or near falls during 6-month follow-up, mean (SD, min-max) & $2.60(8.01,0-50)$ & $2.43(4.51,0-25)$ & $0.081^{\mathrm{a}}$ \\
\hline
\end{tabular}

FOGQsa Freezing of Gait Questionnaire, HY Hoehn \& Yahr, MMSE Mini-Mental State Exam, NRT Nutt Retropulsion Test, UPDRS Unified Parkinson's Disease Rating Scale, 10MWT 10-m Walk Test

${ }^{\mathrm{a}}$ Wilcoxon signed-rank test

bMcNemar's test

${ }^{\mathrm{c}}$ Tomlinson et al. (2010) 
Table 3 Poisson regression analyses of potential short-term predictors (Assessment 1) of the number of future falls and/or near falls during the following 6 months $(n=58)$

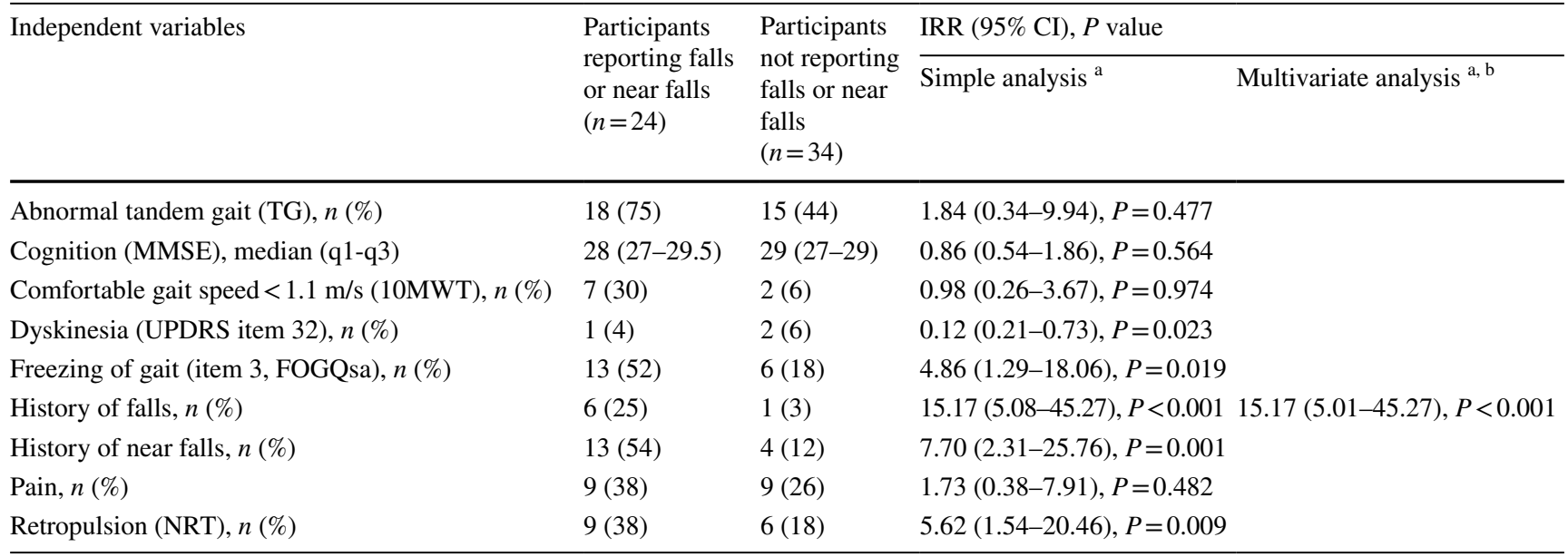

FOGQsa Freezing of Gait Questionnaire, IRR incidence rate ratio, MMSE Mini-Mental State Exam, NRT Nutt Retropulsion Test, UPDRS Unified Parkinson's Disease Rating Scale, 10MWT 10-m Walk Test

${ }^{a}$ For the regression analysis, scores were adjusted to be in the same direction

${ }^{\mathrm{b}}$ Multiple Poisson regression analysis (backward stepwise deletion method). Final model goodness-of-fit (Omnibus test), $P<0.001 ; R^{2}$ deviance, 0.459

Table 4 Poisson regression analyses of potential short-term predictors (Assessment 2) of the number of falls and/or near falls during the following 6 months $(n=58)$

\begin{tabular}{|c|c|c|c|c|}
\hline \multirow[t]{2}{*}{ Independent variables } & \multirow{2}{*}{$\begin{array}{l}\text { Participants } \\
\text { reporting falls } \\
\text { or near falls } \\
(n=28)\end{array}$} & \multirow{2}{*}{$\begin{array}{l}\text { Participants not } \\
\text { reporting falls or } \\
\text { near falls } \\
(n=30)\end{array}$} & \multicolumn{2}{|l|}{ IRR $(95 \% \mathrm{CI}), P$ value } \\
\hline & & & Simple analysis ${ }^{\text {a }}$ & Multivariate analysis ${ }^{\mathrm{a}, \mathrm{b}}$ \\
\hline Abnormal tandem gait (TG), $n(\%)$ & $22(79)$ & $16(53)$ & $4.17(1.49-11.66), P=0.007$ & $3.77(1.47-9.67), P=0.006$ \\
\hline Cognition (MMSE), median (q1-q3) & $27.5(26.5-28.5)$ & $28(28-29)$ & $1.19(1.05-1.34), P=0.006$ & $1.17(1.03-1.36), P=0.019$ \\
\hline Comfortable gait speed $<1.1 \mathrm{~m} / \mathrm{s}(10 \mathrm{MWT}), n(\%)$ & $14(50)$ & $10(33)$ & $2.33(0.85-6.44), P=0.101$ & \\
\hline Dyskinesia (UPDRS IV item 32), $n(\%)$ & $14(50)$ & $7(23)$ & $2.14(0.84-5.44), P=0.109$ & \\
\hline Freezing of gait (item 3, FOGQsa), $n(\%)$ & $20(71)$ & $9(30)$ & $2.98(1.05-8.45), P=0.039$ & \\
\hline History of falls, $n(\%)$ & $15(54)$ & $8(26)$ & $3.29(1.38-7.83), P=0.007$ & \\
\hline History of near falls, $n(\%)$ & $23(82)$ & $14(47)$ & $2.15(0.75-6.21), P=0.156$ & \\
\hline Pain, $n(\%)$ & $10(38)$ & $11(37)$ & $1.06(0.39-2.89), P=0.904$ & \\
\hline Retropulsion (NRT), $n(\%)$ & $13(46)$ & $6(20)$ & $3.39(1.46-7.84), P=0.004$ & \\
\hline
\end{tabular}

FOGQsa Freezing of Gait Questionnaire, IRR incidence rate ratio, MMSE Mini-Mental State Exam, NRT Nutt Retropulsion Test, UPDRS Unified Parkinson's Disease Rating Scale, 10MWT 10-m Walk Test

${ }^{a}$ For the regression analysis, scores were adjusted to be in the same direction

${ }^{\mathrm{b}}$ Multiple Poisson regression analysis (backward stepwise deletion method). Final model goodness-of-fit (Omnibus test), $P<0.001 ; R^{2}$ deviance, 0.079

\section{Long-time predictors}

The univariate Poisson regression analysis based on A1 and F2 data identified six predictors associated with the number of falls and near falls at $P<0.2$ (Table 5). The multivariate Poisson regression analysis identified a model including two significant predictors of the number of falls and/or near falls over 6 months 3.5 years later: abnormal TG (IRR, 7.79) and lower MMSE scores (IRR, 1.49) (Table 5). 
Table 5 Poisson regression analyses of potential long-term predictors (Assessment 1) of the number of falls and/or near falls during 6 months 3.5 years later $(n=58)$

\begin{tabular}{|c|c|c|c|c|}
\hline \multirow[t]{2}{*}{ Independent variables } & \multirow{2}{*}{$\begin{array}{l}\text { Participants } \\
\text { reporting falls } \\
\text { or near falls } \\
(n=28)\end{array}$} & \multirow{2}{*}{$\begin{array}{l}\text { Participants not } \\
\text { reporting falls or } \\
\text { near falls }(n=30)\end{array}$} & \multicolumn{2}{|l|}{ IRR $(95 \% \mathrm{CI}), P$ value } \\
\hline & & & Simple analysis ${ }^{\mathrm{a}}$ & Multivariate analysis ${ }^{\mathrm{a}, \mathrm{b}}$ \\
\hline Abnormal tandem gait (TG), $n(\%)$ & $20(71)$ & $13(43)$ & $5.53(2.26-13.49), P<0.001$ & 7.79 (2.90-20.91), $P<0.001$ \\
\hline Cognition (MMSE), median (q1-q3) & $28(27-29)$ & $29(27-29)$ & $1.37(1.12-1.68), P=0.002$ & 1.49 (1.28-1.73), $P<0.001$ \\
\hline Comfortable gait speed $<1.1 \mathrm{~m} / \mathrm{s}(10 \mathrm{MWT}), n(\%)$ & $7(25)$ & $2(7)$ & $5.86(2.67-12.82), P<0.001$ & \\
\hline Dyskinesia (UPDRS IV item 32), $n(\%)$ & $2(7)$ & $1(3)$ & $3.13(0.80-12.20), P=0.100$ & \\
\hline Freezing of gait (item 3, FOGQsa), $n(\%)$ & $12(45)$ & $7(23)$ & $3.12(1.33-7.28), P=0.009$ & \\
\hline History of falls, $n(\%)$ & $6(21)$ & $1(3)$ & $1.14(0.50-2.57), P=0.762$ & \\
\hline History of near falls, $n(\%)$ & $12(43)$ & $5(17)$ & $2.25(0.90-5.58), P=0.081$ & \\
\hline Pain, $n(\%)$ & $11(39)$ & $7(23)$ & $1.60(0.64-4.00), P=0.316$ & \\
\hline Retropulsion (NRT), $n(\%)$ & $8(29)$ & $7(23)$ & $1.30(0.40-4.24), P=0.663$ & \\
\hline
\end{tabular}

FOGQsa Freezing of Gait Questionnaire, IRR incidence rate ratio, MMSE Mini-Mental State Exam, NRT Nutt Retropulsion Test, UPDRS Unified Parkinson's Disease Rating Scale, 10MWT 10-m Walk Test

${ }^{a}$ For the regression analysis, scores were adjusted to be in the same direction

${ }^{b}$ Multiple Poisson regression analysis (backward stepwise deletion method). Final model goodness-of-fit (Omnibus test), $P<0.001 ; \mathrm{R}^{2}$ deviance, 0.369

\section{Discussion}

In this prospective cohort study with PwPD, we found history of falls to be a strong short-term predictor of the number of falls and/or near falls in earlier stages of PD, whereas abnormal TG and cognition were identified as both shortand long-term predictors in later stages of the disease.

In earlier stages of PD, we found that a person reporting history of falls could be expected, on average, to experience approximately 15 times as many falls and/or near falls during the following 6 months than a person without history of falls. This is in line with prior findings, demonstrating that history of falls is associated with higher frequencies of future falls in PD $[1,14,15]$. Thus, history of falls, the most robust predictor of future falling in PD [28], was confirmed as a strong predictor also of the number of falls/near falls at the earlier course of disease. However, the data generated 3.5 years later yielded a prediction model with abnormal TG as a strongest predictor followed by cognitive decline, whereas history of falls did not contribute to the prediction of the number of falls/near falls over the next 6 months, once TG and cognition were taken into account. This model suggested that the person with abnormal TG could be expected to experience approximately 3.8 times as many falls and/or near falls during following 6 months as a person with normal TG performance. The corresponding value for cognitive decline was 1.2 for a one-unit decrease in MMSE score. The difference in identified short-term predictors in these two models may be related to differences in the frequencies of falls due to disease progression [14]. Indeed, our sample had significantly more motor symptoms and reported more than twice as many falls in the later course of the disease compared to baseline. Based on observations from the baseline assessment and the second follow-up 3.5 years later, these variables were also identified as long-term predictors, suggesting that number of falls and/or near falls is almost 7.8 times higher for a person with abnormal TG and 1.5 times higher for a one-unit decrease in MMSE score. Again, history of falls did not contribute to the long-term prediction once TG and cognition were taken into account.

To the best of our knowledge, the association between TG and frequency of falls/near falls in PD has not been reported before. However, Lindholm et al. reported a prediction model suggesting that abnormal TG is associated with a fourfold higher risk of the occurrence of future falls and/or near falls in early PD [7]. The baseline prevalence of abnormal TG in our sample was high (57\%). This result is in line with previous findings [29-31] and suggests that abnormal TG may be a marker of impaired balance in early PD [30].

The critical point of TG is the exact foot placement [32] and ability to keep center of mass (COM) within a very narrow base of support that challenges the mediolateral balance [33, 34]. Normal gait, including ability to walk heel-to-toe, requires that multiple systems, both central and peripheral, are able to function normally and in interaction [35]. Recent results from spatiotemporal analysis of TG suggest that mediolateral balance in PD is impaired compared with healthy controls, and among PwPD with FOG compared to those without FOG [29]. Interestingly, in our study, the prevalence of FOG had increased at 3.5 years, which may have contributed to the 
associations between TG and the number of falls/near falls. Also, other PD-related complications such as striatal foot deformities, with toe curling, foot inversion, pain, and shortening of muscles [36] may impair TG performance [37]. Furthermore, comorbidities such as vestibular dysfunction, peripheral neuropathies, and age-related musculoskeletal changes are also associated with abnormal TG [35]. All these factors that affect mediolateral balance may also aggravate PD-related postural instability in the lateral direction [38]. Thus, TG may add important information to already existing assessment of postural stability that usually includes shoulder pull in backward direction [21]. This was probably reflected in the strong association between abnormal TG and the number of falls/near falls in our long-term prediction model, and supports the suggestion that abnormal TG may be an indicator of impending disease progression [30].

The second predictor in our models was cognitive decline. Our results suggest that every decrease in the MMSE score results in approximately $1.2-1.5$ times higher number of falls/near falls. To our knowledge, this is a novel finding not reported before, although MMSE scores lower than 24 have been associated with an almost sevenfold higher risk of the occurrence of future falls in PD [13].

Some variables that were significant short- and/or longterm predictors of the number of falls/near falls in univariate but not in the multivariate analyses may need a special attention. For example, FOG and comfortable gait speed $<1.1 \mathrm{~m} / \mathrm{s}$ together with history of falls are included in the three-step falls prediction model $[5,7,10]$. Both FOG and low gait speed may be related to poor TG performance; FOG directly due to PD specific central mechanisms [29] and low gait speed may (in addition to PD-related brady-/ hypokinesia) be due to non-PD specific pathologies such as peripheral neuropathies or vestibular dysfunction [39, 40]. These pathologies may aggravate PD-related gait disorders and worsen TG performance [35]. Thus, TG seems to be sensitive to both PD specific and nonspecific aspects of gait and balance disorders in PD, and abnormal TG performance should alert clinicians to consider potential reasons and initiate appropriate therapy.

Taken together, TG and MMSE are both well-known and easily performed clinical tests that predict the number of falls and/or near falls in PD. These tests seem to be stable predictors over time and may also serve as markers of disease progression. They may, therefore, be of special interest to use in clinical settings as predictive screening tests of increased number of falls/near falls. Such information should serve as a starting point for in-depth examination of additional motor and cognitive symptoms such as FOG [29], striatal foot deformities [36, 37], neuropathies [39], dizziness [40], and impaired executive function [11, 41], and may facilitate the rapid implementation of fall prevention strategies [42]. However, further longitudinal studies are needed to explore the external validity of these tests in broader ranges of PD severities and over longer periods of time.

\section{Limitations}

The PwPD in this study had relatively mild PD, and people above the age of 80 years were not included at the start of this study. Our findings may thus not apply to older people or those with more severe PD. However, focusing on PwPD with relatively mild PD has been recommended to work proactively $[28,43]$.

The number of PwPD that declined participation was high. This means that there is a risk of selection bias and that our sample may not represent the underlying population of PD patients and reduces statistical power and precision in estimates.

Several of the predictors were represented by relatively coarse indicators. Using a coarse indicator, one may not capture those having mild problems. For instance, it has been suggested that the Montreal Cognitive Assessment is preferable to the MMSE when screening for early cognitive impairments in PD [44]. Furthermore, there may well be other predictors of relevance in relation to the aim of this study that were not included in our protocol. However, this is a general limitation with essentially any observational study of this kind, and the included predictors were selected based on clinical experience and what was known from the previous studies at the time.

\section{Conclusion}

In this prospective cohort study with PwPD, we found that abnormal TG and cognitive decline predict the number of falls and/or near falls in the short as well as the long term. History of falls is also a strong short-term predictor but only in earlier stages of the disease. Our observations provide important additions to the evidence base for clinical fall prediction in PD.

Acknowledgments This work was supported by grants from the Stoltz foundation (Department of Neurology and Rehabilitation Medicine, Malmö, Skåne University Hospital, Sweden), Skåne County Council's research and development foundation, the Promobilia foundation, the Swedish Parkinson Foundation, the Swedish Parkinson Academy, the Academy of Caring Sciences (Skåne University Hospital, Sweden), and Kristianstad University. None of the funders had any role in the study design, data collection and analysis, decision to publish, or preparation of the manuscript. The authors are grateful to all patients and caregivers for their contribution to this study. Special thanks are due to Wojciech Duzynski (M.D., Ph.D) and Eva Berg (RN) for assistance with participant selection. 
Author contributions BL: research project: conception, organization, execution; statistical analysis: design, execution, review, and critique; manuscript preparation: writing of the first draft, review, and critique. $\mathrm{CB}$ and PO: statistical analysis: review and critique, and manuscript preparation: review and critique; $\mathrm{PH}$ : research project: conception, statistical analysis: design, execution, review, and critique, and manuscript preparation: review and critique.

Funding Open access funding provided by Lund University.

\section{Compliance with ethical standards}

Conflicts of interest The authors have declared that no competing interests exist.

Ethical approval The study was approved by the institutional review board and was performed in accordance with the ethical standards laid down in the 1964 Declaration of Helsinki and its later amendments.

Informed consent Obtained.

Open Access This article is licensed under a Creative Commons Attribution 4.0 International License, which permits use, sharing, adaptation, distribution and reproduction in any medium or format, as long as you give appropriate credit to the original author(s) and the source, provide a link to the Creative Commons licence, and indicate if changes were made. The images or other third party material in this article are included in the article's Creative Commons licence, unless indicated otherwise in a credit line to the material. If material is not included in the article's Creative Commons licence and your intended use is not permitted by statutory regulation or exceeds the permitted use, you will need to obtain permission directly from the copyright holder. To view a copy of this licence, visit http://creativecommons.org/licenses/by/4.0/.

\section{References}

1. Voss TS, Elm JJ, Wielinski CL, Aminoff MJ, Bandyopadhyay D, Chou KL, Sudarsky LR, Tilley BC, Falls Writing Group NNETPDI (2012) Fall frequency and risk assessment in early Parkinson's disease. Parkinsonism Relat Disord 18(7):837-841. https:// doi.org/10.1016/j.parkreldis.2012.04.004

2. Song J, Sigward S, Fisher B, Salem GJ (2012) Altered dynamic postural control during step turning in persons with early-stage Parkinson's disease. Parkinsons Dis 2012:386962. https://doi. org/10.1155/2012/386962

3. Hely MA, Morris JG, Traficante R, Reid WG, O'Sullivan DJ, Williamson PM (1999) The sydney multicentre study of Parkinson's disease: progression and mortality at 10 years. J Neurol Neurosurg Psychiatry 67(3):300-307

4. Allen NE, Schwarzel AK, Canning CG (2013) Recurrent falls in Parkinson's disease: a systematic review. Parkinsons Dis 2013:906274. https://doi.org/10.1155/2013/906274

5. Paul SS, Canning CG, Sherrington C, Lord SR, Close JC, Fung VS (2013) Three simple clinical tests to accurately predict falls in people with Parkinson's disease. Mov Disord 28(5):655-662. https://doi.org/10.1002/mds.25404

6. Lindholm B, Hagell P, Hansson O, Nilsson MH (2015) Prediction of falls and/or near falls in people with mild Parkinson's disease. PLoS ONE 10(1):e0117018. https://doi.org/10.1371/journ al.pone. 0117018
7. Lindholm B, Nilsson MH, Hansson O, Hagell P (2016) External validation of a 3-step falls prediction model in mild Parkinson's disease. J Neurol 263(12):2462-2469. https://doi.org/10.1007/ s00415-016-8287-9

8. Lindholm B, Eek F, Skogar O, Hansson EE (2019) Dyskinesia and FAB score predict future falling in Parkinson's disease. Acta Neurol Scand 139(6):512-518. https://doi.org/10.1111/ ane. 13084

9. Lindholm B, Nilsson MH, Hansson O, Hagell P (2018) The clinical significance of 10-m walk test standardizations in Parkinson's disease. J Neurol 265(8):1829-1835. https://doi.org/10.1007/ s00415-018-8921-9

10. Duncan RP, Cavanaugh JT, Earhart GM, Ellis TD, Ford MP, Foreman KB, Leddy AL, Paul SS, Canning CG, Thackeray A, Dibble LE (2015) External validation of a simple clinical tool used to predict falls in people with Parkinson disease. Parkinsonism Relat Disord 21(8):960-963. https://doi.org/10.1016/j.parkreldis .2015.05.008

11. Domingos JM, Godinho C, Dean J, Coelho M, Pinto A, Bloem BR, Ferreira JJ (2015) Cognitive impairment in fall-related studies in Parkinson's disease. J Parkinsons Dis 5(3):453-469. https://doi. org/10.3233/JPD-150590

12. Arevalo-Rodriguez I, Smailagic N, Roque IFM, Ciapponi A, Sanchez-Perez E, Giannakou A, Pedraza OL, Bonfill Cosp X, Cullum S (2015) Mini-Mental State Examination (MMSE) for the detection of Alzheimer's disease and other dementias in people with mild cognitive impairment (MCI). Cochrane Database Syst Rev 3:CD010783. https://doi.org/10.1002/14651858.CD010783. pub2

13. Wood BH, Bilclough JA, Bowron A, Walker RW (2002) Incidence and prediction of falls in Parkinson's disease: a prospective multidisciplinary study. J Neurol Neurosurg Psychiatry 72(6):721-725

14. Almeida LRS, Heller G, Allen NE, Canning CG, Sherrington C, Valenca GT, Oliveira-Filho J, Paul SS (2019) Predicting falls in people with Parkinson's disease: impact of methodological approaches on predictors identified. Aging Clin Exp Res. https:// doi.org/10.1007/s40520-019-01281-9

15. Paul SS, Allen NE, Sherrington C, Heller G, Fung VS, Close JC, Lord SR, Canning CG (2014) Risk factors for frequent falls in people with Parkinson's disease. J Parkinsons Dis 4(4):699-703. https://doi.org/10.3233/JPD-140438

16. Torsney KM, Noyce AJ, Doherty KM, Bestwick JP, Dobson R, Lees AJ (2014) Bone health in Parkinson's disease: a systematic review and meta-analysis. J Neurol Neurosurg Psychiatry 85(10):1159-1166. https://doi.org/10.1136/jnnp-2013-307307

17. Huang YF, Cherng YG, Hsu SP, Yeh CC, Chou YC, Wu CH, Chen TL, Liao CC (2015) Risk and adverse outcomes of fractures in patients with Parkinson's disease: two nationwide studies. Osteoporos Int 26(6):1723-1732. https://doi.org/10.1007/s0019 8-015-3052-y

18. Hughes AJ, Daniel SE, Kilford L, Lees AJ (1992) Accuracy of clinical diagnosis of idiopathic Parkinson's disease: a clinicopathological study of 100 cases. J Neurol Neurosurg Psychiatry 55(3):181-184

19. Tomlinson CL, Stowe R, Patel S, Rick C, Gray R, Clarke CE (2010) Systematic review of levodopa dose equivalency reporting in Parkinson's disease. Mov Disord 25(15):2649-2653. https://doi. org/10.1002/mds. 23429

20. Folstein MF, Folstein SE, McHugh PR (1975) "Mini-mental state". A practical method for grading the cognitive state of patients for the clinician. J Psychiatr Res 12(3):189-198. https:// doi.org/10.1016/0022-3956(75)90026-6

21. Fahn S, Elton R, et al (1987) Unified Parkinson's Disease Rating Scale. In: Fahn S, Marsden CD, Calne D, Goldstein M (eds) Recent developments in Parkinson's disease, vol 2. McMillan Healthcare Information, Florham Park, NJ, pp 153-163, 293-304 
22. Nilsson MH, Hagell P (2009) Freezing of Gait Questionnaire: validity and reliability of the Swedish version. Acta Neurol Scand 120(5):331-334. https://doi.org/10.1111/j.1600-0404.2009.01175 . $\mathrm{x}$

23. Lamb SE, Jorstad-Stein EC, Hauer K, Becker C (2005) Development of a common outcome data set for fall injury prevention trials: the Prevention of Falls Network Europe consensus. J Am Geriatr Soc 53(9):1618-1622. https://doi.org/10.111 $1 / j .1532-5415.2005 .53455 . x$

24. Gray P, Hildebrand K (2000) Fall risk factors in Parkinson's disease. J Neurosci Nurs 32(4):222-228

25. Hoehn MM, Yahr MD (2001) Parkinsonism: onset, progression, and mortality 1967 . Neurology 57(10 Suppl 3):S11-26

26. Hosmer DW, Lemeshow S, Sturdivant RX (2013) Applied logistic regression, 4th edn. Wiley, New Jersey

27. Norman GR, Streiner DL (2014) Biostatistics: the bare essentials, 4th edn. People's Medical Publishing House, Beijing

28. Pickering RM, Grimbergen YA, Rigney U, Ashburn A, Mazibrada G, Wood B, Gray P, Kerr G, Bloem BR (2007) A meta-analysis of six prospective studies of falling in Parkinson's disease. Mov Disord 22(13):1892-1900. https://doi.org/10.1002/mds.21598

29. Sharma R, Pillai L, Glover A, Virmani T (2019) Objective impairment of tandem gait in Parkinson's disease patients increases with disease severity. Parkinsonism Relat Disord 68:33-39. https://doi. org/10.1016/j.parkreldis.2019.09.023

30. Margolesky J, Bette S, Shpiner DS, Jordan EA, Dong C, Rundek T, Luca CC, Moore H, Singer C (2019) Tandem gait abnormality in Parkinson disease: prevalence and implication as a predictor of fall risk. Parkinsonism Relat Disord 63:83-87. https://doi. org/10.1016/j.parkreldis.2019.02.034

31. Ehm G, Lee WW, Jin Jung Y, Kim HJ, Jeon B (2019) Clinical differences in patients with Parkinson's disease according to tandem gait performance. J Clin Neurosci 60:93-95. https://doi. org/10.1016/j.jocn.2018.09.022

32. Stolze H, Klebe S, Petersen G, Raethjen J, Wenzelburger R, Witt K, Deuschl G (2002) Typical features of cerebellar ataxic gait. J Neurol Neurosurg Psychiatry 73(3):310-312

33. Yang JF, Winter DA, Wells RP (1990) Postural dynamics of walking in humans. Biol Cybern 62(4):321-330. https://doi. org/10.1007/bf00201446

34. Winter D (1995) Human balance and posture control during standing and walking. Gait Posture 3:193-214
35. Margolesky J, Singer C (2018) How tandem gait stumbled into the neurological exam: a review. Neurol Sci 39(1):23-29. https:// doi.org/10.1007/s10072-017-3108-1

36. Ashour R, Tintner R, Jankovic J (2005) Striatal deformities of the hand and foot in Parkinson's disease. Lancet Neurol 4(7):423-431. https://doi.org/10.1016/S1474-4422(05)70119-8

37. Lindholm B, Beckman A, Duzynski W, Ekvall Hansson E (2016) Outcome on balance and gait of botulinum toxin treatment for striatal foot in Parkinson's disease. Mov Disord Clin Pract. https ://doi.org/10.1002/mdc3.1241

38. Horak FB, Dimitrova D, Nutt JG (2005) Direction-specific postural instability in subjects with Parkinson's disease. Exp Neurol 193(2):504-521. https://doi.org/10.1016/j.expneurol.2004.12.008

39. Suda EY, Matias AB, Bus SA, Sacco ICN (2019) Impact of diabetic neuropathy severity on foot clearance complexity and variability during walking. Gait Posture 74:194-199. https://doi. org/10.1016/j.gaitpost.2019.09.014

40. Coelho AR, Perobelli JLL, Sonobe LS, Moraes R, Barros CGC, Abreu DCC (2020) Severe dizziness related to postural instability, changes in gait and cognitive skills in patients with chronic peripheral vestibulopathy. Int Arch Otorhinolaryngol 24(1):e99 e106. https://doi.org/10.1055/s-0039-1695025

41. Yarnall AJ, Breen DP, Duncan GW, Khoo TK, Coleman SY, Firbank MJ, Nombela C, Winder-Rhodes S, Evans JR, Rowe JB, Mollenhauer B, Kruse N, Hudson G, Chinnery PF, O'Brien JT, Robbins TW, Wesnes K, Brooks DJ, Barker RA, Burn DJ, Group I-PS (2014) Characterizing mild cognitive impairment in incident Parkinson disease: the ICICLE-PD study. Neurology 82(4):308 316. https://doi.org/10.1212/WNL.0000000000000066

42. Hulbert S, Rochester L, Nieuwboer A, Goodwin V, Fitton C, Chivers-Seymour K, Ashburn A (2019) "Staying safe"-a narrative review of falls prevention in people with Parkinson's"PDSAFE". Disabil Rehabil 41(21):2596-2605. https://doi. org/10.1080/09638288.2018.1471167

43. Kerr GK, Worringham CJ, Cole MH, Lacherez PF, Wood JM, Silburn PA (2010) Predictors of future falls in Parkinson disease. Neurology 75(2):116-124. https://doi.org/10.1212/WNL.0b013 e3181e7b688

44. Lessig S, Nie D, Xu R, Corey-Bloom J (2012) Changes on brief cognitive instruments over time in Parkinson's disease. Mov Disord 27(9):1125-1128. https://doi.org/10.1002/mds.25070 